\title{
Trigeminal Autonomic Cephalalgias: Beyond the Conventional Treatments
}

\author{
Sarah Miller • Manjit Matharu
}

Published online: 29 June 2014

(C) The Author(s) 2014. This article is published with open access at Springerlink.com

\begin{abstract}
The trigeminal autonomic cephalalgias include cluster headache, paroxysmal hemicrania, short-lasting unilateral neuralgiform headache attacks, and hemicrania continua. While the majority responds to conventional pharmacological treatments, a small but significant proportion of patients are intractable to these treatments. In these cases, alternative choices for these patients include oral and injectable drugs, lesional or resectional surgery, and neurostimulation. The evidence base for conventional treatments is limited, and the evidence for those used beyond convention is more so. At present, the most evidence exists for nerve blocks, deep brain stimulation, occipital nerve stimulation, sphenopalatine ganglion stimulation in chronic cluster headache, and microvascular decompression of the trigeminal nerve in short-lasting unilateral neuralgiform headache attacks.
\end{abstract}

Keywords Trigeminal autonomic cephalalgias . Neurostimulation $\cdot$ Nerve blocks $\cdot$ Sphenopalatine ganglion stimulation · Occipital nerve stimulation · Deep brain stimulation

\section{Introduction}

Trigeminal autonomic cephalalgias (TACs) are primary headache disorders characterized by unilateral head pain occurring

This article is part of the Topical Collection on Trigeminal Autonomic Cephalalgias

S. Miller $\cdot$ M. Matharu $(\bowtie)$

Headache Group, Institute of Neurology, Queen Square,

London WC1N 3BG, UK

e-mail: m.matharu@uclmail.net

S. Miller · M. Matharu

The National Hospital for Neurology and Neurosurgery, Queen

Square, London WC1N 3BG, UK in association with ipsilateral cranial autonomic symptoms. TACs include cluster headache $(\mathrm{CH})$, paroxysmal hemicrania $(\mathrm{PH})$, and short-lasting unilateral neuralgiform headache attacks [including both short-lasting unilateral neuralgiform headache attacks with conjunctival injection and tearing (SUNCT), and short-lasting unilateral headache attacks with cranial autonomic symptoms (SUNA)], and hemicrania continua (HC) [1]. The clinical features of these attacks and their response to medications are often distinctly characteristic (Table 1).

The majority of patients will respond to standard or firstline treatments, as outlined in international guidelines (Table 1) [2]. A small, but highly disabled, group of patients will fail to respond to these treatments, and this has led to the search for alternative treatments.

Standard treatment recommendations for TACs are based on moderate-to-low quality evidence, with little in the way of randomized trials. These will not be covered in this article but were recently reviewed by Pareja and Alvarez [3••]. Nonconventional treatments are used on the basis of clinical experience and open-label series. The nonconventional treatments currently in clinical use are reviewed here.

\section{CH}

$\mathrm{CH}$ consist of attacks of severe, strictly unilateral pain occurring in the orbital, supraorbital and temporal regions, lasting 15-180 minutes, and that occur from once every other day to eight times daily [1]. The pain is associated with autonomic features and agitation (Table 1).

Acute Treatment

The conventional acute treatments for $\mathrm{CH}$ attacks are shown in Table 1. When these fail, other options are scarce. Intranasal 
Table 1 Clinical features of the trigeminal autonomic cephalalgias and first-line treatments

\begin{tabular}{|c|c|c|c|c|}
\hline & Cluster headache & $\begin{array}{l}\text { Paroxysmal } \\
\text { hemicrania }\end{array}$ & $\begin{array}{l}\text { Hemicrania } \\
\text { continua }\end{array}$ & $\begin{array}{l}\text { Short-lasting unilateral } \\
\text { neuralgiform headache attacks } \\
\text { (SUNCT/SUNA) }\end{array}$ \\
\hline ICHD-3 beta Code & 3.1 & 3.2 & 3.4 & $\begin{array}{l}3.3 \\
\text { SUNCT } 3.3 .1 \\
\text { SUNA } 3.3 .2\end{array}$ \\
\hline $\operatorname{Sex}(F: M)$ & $1: 5-7$ & $1: 1$ & $2: 1$ & $1: 2$ \\
\hline $\begin{array}{l}\text { Pain Type } \\
\text { Severity }\end{array}$ & $\begin{array}{l}\text { Stabbing, boring } \\
\text { Severe }\end{array}$ & $\begin{array}{l}\text { Throbbing, stabbing, } \\
\text { boring } \\
\text { Moderate-severe }\end{array}$ & $\begin{array}{l}\text { Throbbing, ache, sharp, pressure } \\
\text { Moderate background with severe } \\
\text { exacerbations }\end{array}$ & $\begin{array}{l}\text { Sharp, shooting, burning } \\
\text { Severe }\end{array}$ \\
\hline Duration and frequency & 15-180 mins, 1-8/day & 2-30 mins, 5-40/day & Continuous & $1-600$ s, $1-200 /$ day \\
\hline Autonomic features & Yes & Yes & Yes with exacerbations & Yes $^{\mathrm{a}}$ \\
\hline Indometacin effect & No & Complete resolution & Complete resolution & No \\
\hline $\begin{array}{l}\text { First choice abortive } \\
\text { agent }\end{array}$ & $\begin{array}{l}\text { Injectable or nasal } \\
\text { sumatriptan } \\
\text { Oxygen }\end{array}$ & Nil & Nil & Nil \\
\hline $\begin{array}{l}\text { First choice preventative } \\
\text { agents }\end{array}$ & $\begin{array}{l}\text { Verapamil } \\
\text { Lithium } \\
\text { Topiramate } \\
\text { Methysergide }^{\mathrm{b}}\end{array}$ & Indometacin & Indometacin & Lamotrigine \\
\hline
\end{tabular}

SUNCT short-lasting unilateral neuralgiform headache attacks with conjunctival injection and tearing, SUNA short-lasting unilateral neuralgiform headache attacks with autonomic symptoms, $I C H D$-3 beta International Classification of Headache Disorders 3rd edition Beta version, $F$ female, $M$ male ${ }^{a}$ SUNCT: both conjunctival injection and tearing; SUNA: only one or neither of conjunctival injection and tearing

${ }^{\mathrm{b}}$ Methysergide is either not available or is due to be withdrawn in several countries

lidocaine has limited evidence [4], and subcutaneous octreotide, a somatostain analogue, was found to be superior to placebo in a single study [5]. Owing to practicalities of administration, both have limited clinical usefulness.

\section{Preventative Treatment}

International guidelines give verapamil, lithium, methysergide, topiramate, valproate, melatonin, and baclofen as firstline treatments [2]. In their review, Pereja and Alvarez describe verapamil, lithium, and topiramate as being the standard treatments most commonly in use [3••]. Below, we shall provide a summary of treatments aside from verapamil, lithium, methysergide, and topiramate (Table 2).

\section{Oral Treatments}

Gabapentin is widely used in the treatment of pain and has therefore been trialled in $\mathrm{CH}$ with some highly positive data in a limited series of patients. In the series of Leandri et al. [6], 12 patients undertook an open trial of gabapentin. All reported freedom from pain after 8 days of treatment. Schuh-Hofer et al. [7] used gapapentin as an adjunctive treatment in eight patients with chronic $\mathrm{CH}(\mathrm{CCH})$ who had failed first-line therapies. Six of eight patients reported a more than $50 \%$ reduction in attack frequency, with two claiming pain freedom at the 4-months follow-up. Doses used by this group ranged from 800 to $3600 \mathrm{mg}$. Long-term data on the use of gabapentin do not exist, but Schuh-Hofer et al. [7] saw that, over a year, follow-up patients did seem to develop tolerance. Although the authors state that gabapentin is a well-tolerated drug the dosage of which can be rapidly increased over a short period of time, in clinical practice their highly positive rapidonset results have not been observed. It is relevant to note that although gabapentin was previously considered beneficial for migraine, both a placebo-controlled study by Silberstein et al. [8] and recent Cochrane review have found no evidence of efficacy [9].

Melatonin has been tried in $\mathrm{CH}$, but there are contradictory findings. Leone et al. [10] found a significant reduction in headache frequency in their 2-week randomized placebo controlled trial, with 5/10 patients with episodic $\mathrm{CH}(\mathrm{ECH})$ treated reporting cessation of their attacks after 5 days of treatment (10 mg daily) but no effect on patients with $\mathrm{CCH}$. Pringsheim et al. [11] conducted a placebo-controlled crossover study using $2 \mathrm{mg}$ daily for 1 month in nine patients. They reported no significant difference between melatonin and placebo. Although conflicting evidence exists, melatonin makes for an attractive therapy given its lack of side effects and drug interactions. An argument can be made that the negative trial group used a very low dose and, in practice, our unit recommends a treatment dose of $12-16 \mathrm{mg}$ daily. Further trials with higher doses need to be carried out before clear recommendations can be made. 


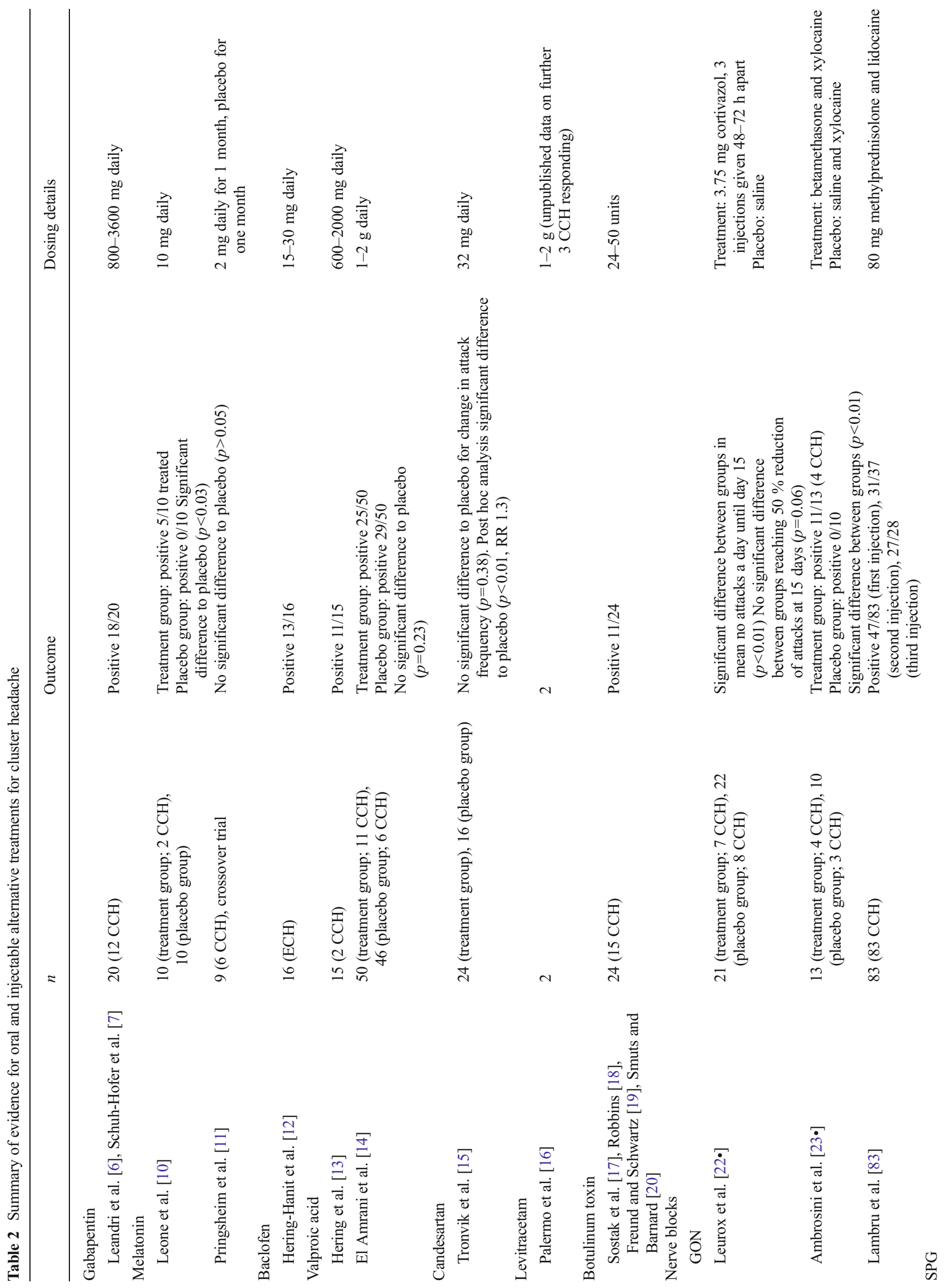


Baclofen has gamma-aminobutyric acid-ergic actions and is used in a variety of nonheadache-related pain conditions. Its use in $\mathrm{CH}$ has been evaluated by Hering-Hanit and Gadoth [12] in an open-label series of 16 patients with ECH. Patients were treated with a 15-30 mg daily dose of baclofen for a 3 -week period. Twelve of the 16 patients reported that their attacks ceased within a week of starting treatment, and one more reported pain freedom by week two. No side effects were reported and the drug seemed to retain its efficacy on repeated use. Tizanadine, an alpha-2 adrenergic agonist, has similar antinociception actions to baclofen in other conditions but is better tolerated. There is no published evidence of its usefulness in $\mathrm{CH}$ but our local experience is of a similar efficacy to baclofen. Again, randomized controlled trials are indicated on both drugs.

Valproic acid (valproate) is a drug used in the treatment of migraine and it has also been evaluated in three reports on $\mathrm{CH}$ treatment. Hering and Kuritzky [13] conducted an open-label study on 15 patients using $600 \mathrm{mg}-2 \mathrm{~g}$ daily of valproate taken until the expected end of their bout (from 2 weeks to 2 months). Eleven patients reacted favorably to treatment; nine were rendered pain free [13]. Although patients reported typical bouts lasting many weeks, there is a possibility that spontaneous remission accounted for the positive response seen in the group. Therefore, El Amrani et al. [14] did a multicenter, double-blind, placebo-controlled study of 96 patients given 1-2 g/day of sodium valproate for a 2 -week treatment period. No difference was observed between the placebo and treatment groups. The response rate in the placebo group was high (62\%), and authors state that this was likely to be due to spontaneous remission and influenced their ability to draw conclusions about the efficacy of the valproate [14]. Until further large-scale, randomized studies are conducted, the use of valproate in $\mathrm{CH}$ is questionable.

Candesartan was investigated by Tronvik et al. [15] in a placebo-controlled, multicenter study. Forty patients with ECH were enrolled but the trial was negative [15]. Given that post hoc analysis showed a difference in the number of attacks in the treatment group, larger studies may prove useful.

Levetiracetam is an antiepileptic drug used for partial and generalized seizures. It has been trialed in neuropathic pain and migraine, with low-quality evidence suggesting its usefulness in both conditions. Recently, Palermo et al. [16] reported two cases of ECH with attacks lasting several months responding to $1 \mathrm{~g}$ daily of levetiracetam given for a 4-month period. Both patients were pain free within a week and remained so 6-8 months following discontinuation of the drug. The same group also reported unpublished data of three patients with $\mathrm{CCH}$ responding to $2 \mathrm{~g}$ daily of levetiracetam. Our local experience is positive, with $3 / 5$ patients treated over the last 6 months responding well, and two failing to respond 
owing to an inability to tolerate the drug's side effects of apparent weight gain and worsening of headaches (unpublished data). Overall, the drug has a very good side effect profile and a low potential for interactions. Although the mechanism of action is unclear, initial open-label data are promising; however, further randomized controlled data are clearly needed.

\section{Injectable Treatments}

Botulinum toxin has been reported to relieve pain in a number of conditions, including headache, and has a licence for use in chronic migraine in the USA and Europe. Only one open-label study has looked at the effect of botulinum toxin in $\mathrm{CH}$. In this study, Sostak et al. [17] treated 12 patients with $\mathrm{CH}$ (9 with $\mathrm{CCH}$ ) with a total of 50 units injected into the temporalis, frontalis, splenium capitis, and trapezius ipsilateral to the headache. A reduction in attack frequency was seen by $3 / 12$ patients, all with $\mathrm{CCH}$, with a response lasting 2-3 months postinjection. Case reports exist in abstract form for $12 \mathrm{pa}-$ tients. These patients were injected with 24-50 units into the temporalis and frontalis muscles [18-20]. Eight patients are reported to have had an improvement, with four patients with ECH having abrupt cessation of their attacks. Although botulinum toxin is an attractive treatment option owing to its potential long action, lack of side effects, and drug interactions, further controlled trials similar to those done in chronic migraine are essential.

\section{Nerve Blocks}

Transitional treatments are required when trying to gain rapid control of attacks either during a short bout or until a preventative agent takes effect. The standard option is oral corticosteroids but these should be prescribed with caution (in our unit a maximum of twice a year) owing to the risk of side effects with prolonged or frequent use. The alternative treatment option is peripheral nerve blockade using local anesthetics, often in combination with corticosteroids.

Occipital nerve blocks are the most widely used and evaluated nerve block in the treatment of headache. The greater (GONB) and lesser occipital nerve blocks have been targeted owing to the physiological connections between the upper cervical nerves and the trigeminal nerves in the trigeminocervical complex. The majority of publications are of case reports or observational studies. The most recent of these, by Lambru et al. [21], looked at the efficacy of GONB in $\mathrm{CCH}$ and found that after the first injection of methylprednisolone and lidocaine, $57 \%$ of patients reported a beneficial response lasting, on average, 21 days. These results were reproduced on repeated injections. Transient worsening of headaches was seen in $6 \%$ of patients.
Two groups have published prospective placebo controlled data. Leroux et al. [22•] randomly allocated 43 patients (15 $\mathrm{CCH}, 28 \mathrm{ECH}$ ) to treatment with three suboccipital injections of steroid given over $72 \mathrm{~h}$ or placebo. A significant difference was found between treatment groups in the number of attacks post-treatment, in the time taken to remission, and in patient satisfaction with treatment [22•]. A reduction in the dose of additional verapamil and rescue medication taken was also seen. Ambrosini et al. [23•] conducted a blinded placebocontrolled trial on 23 patients. A single injection of suboccipital steroid led to complete attack suppression in $80 \%$ of patients, with remission lasting at least 4 weeks.

Safety data on GONB are, on the whole, favorable; however, it is as yet unclear as to whether the blocks are better given as a series or a single injection. In the routine clinic setting it is often difficult to organize repeated injections, and larger studies would be needed to change the current practice of single injections.

Other sites used for nerve blocks include supraorbital, auriculotemporal and supratrochler blocks, although no controlled evidence exists for their use. Sphenopalatine ganglion (SPG) blockades have been used to terminate $\mathrm{CH}$ since the early 1900s but are clinically difficult to perform. Devoghel [24] published a series of 120 blocks and reported a response rate of $85 \%$. Pipolo et al. [25] reported a series of 15 patients undergoing endoscopic SPG block for $\mathrm{CH}$ in which $54 \%$ experienced complete remission for between 1 and 28 months. Although not widely used, this and the increasingly positive data emerging from SPG stimulation, may mean that SPG blocks should be considered as part of the treatment arsenal for refractive patients.

\section{Resectional and Ablative Surgery}

The disabling nature of $\mathrm{CH}$ has led many surgeons to target the trigeminal nerve in a bid for pain control. Trigeminal nerve root section was the traditional option for refractory $\mathrm{CCH}$ prior to the advent of neuromodulation. Jarrar et al. [26] reported that $76 \%$ of their 17 patients with $\mathrm{CCH}$ experienced long-term full or near complete pain relief. However, adverse effects were dramatic, with one death, cerebrospinal fluid leaks, and a case of meningitis. Another widely reported adverse outcome of this type of surgery is corneal anesthesia; in the series of Jarrar et al., two patients needed surgery for this complication in order to prevent blindness. Other groups have reported negative outcomes with $\mathrm{CH}$ continuing after trigeminal nerve root section [27].

Kano et al. [28] reviewed stereotactic Gamma knife radiosurgery of the trigeminal and SPG for $\mathrm{CCH}$ in 2011 and concluded that Gamma knife for $\mathrm{CCH}$ was a minimally invasive and potentially attractive alternative to nerve root section, with $60 \%$ of patients reporting long-lasting pain relief. However, they found that $\mathrm{CCH}$ patients were far more likely to 
suffer facial sensory disturbances postoperatively than those with trigeminal neuralgia ( $50 \%$ compared with $10 \%$ ) [28]. A similar review by McClelland et al. [29] was less positive, finding that any initial benefit regressed with time, leaving none of their nine patients reporting $>50 \%$ improvement by 2 weeks -2 years post-treatment, with $50 \%$ of patients suffering some trigeminal nerve dysfunction as a consequence of surgery. However promising the immediate results of trigeminal nerve surgery may appear, the adverse effects and longterm outcomes are consistently poor, and with neuromodulation producing favorable results in terms of safety and follow-up, this sort of surgery should very much be at the bottom of any treatment list, if conducted at all.

\section{Neurostimulation}

Occipital nerve stimulation (ONS) is a nondestructive surgical option for refractory $\mathrm{CCH}$ with an increasing evidence base of open-label studies. Burns et al. [30•] first examined the role of ONS in $\mathrm{CCH}$ in a series of 14 patients. Ten reported benefit, three a benefit of $>90 \%$, and three of $>40 \%$. Magis et al. [31] followed up 14 patients over an average of 37 months and reported 11 to be receiving an at least $90 \%$ reduction in attacks. From these and other series available, ONS appears to be safe, with the most frequent adverse effects reported being dependent on surgical experience and battery depletion, which is overcome by the introduction of rechargeable batteries. A number of series report a side-shift in attacks if unilateral stimulation is employed, and so bilateral lead placement is now standard. A review of the current literature on ONS is given by Magis and Schoenen [32••].

The SPG has also been a target for neuromodulation owing to its links with the trigeminovascular system. Ansarinia et al. [33] investigated SPG stimulation in six patients and found that complete resolution of pain was seen within 3 mins in 11/ 18 attacks treated. A larger, multicenter, sham-controlled study was published in 2013 on the use of on-demand SPG stimulation. A novel device was implanted in 28 patients who randomly received full, sham, or subperception stimulation. There was a significant difference in the number of resolving attacks in the treated group. Sixty eight percent of treated patients had clinically significant resolution of attacks. Adverse events were mild, with $81 \%$ reporting transient facial sensory disturbance and only five cases requiring surgical revision for lead migration or explanation [34••]. Unexpectedly, many patients demonstrated a reduction in attack frequency following regular use of SPG stimulation despite the study being designed to treat acute attacks. Further work is ongoing into the prophylactic efficacy of SPG stimulation.

Deep brain stimulation (DBS) in $\mathrm{CCH}$ stems from imaging findings showing the posterior hypothalamus becoming overactive in attacks [35]. Leone et al. [36] reported the first case in 2001 , and there are now $>60$ published cases. A recent review of DBS was included in the review by Magis and Schoenen [32••]. The overall clinical success rate is around $66 \%$ (mean follow-up 2 years) with a mean delay to clinical result of 42 days. The only placebo-controlled trial of DBS randomized 11 patients to active or sham stimulation for 2 months. No difference was found between groups [37], but, given the findings of other series of time delays to response of $1-$ 86 days, this is thought likely to be due to the short treatment phase. The most commonly reported adverse effects are transient dizziness and visual disturbance associated with amplitude changes.

However, DBS is not without serious risk, with one patient dying from intracerebral hemorrhage postoperatively [38]. With collated data on DBS for $\mathrm{CCH}$ the risk for serious hemorrhage is $3 \%$, which is within the range reported for DBS for movement disorders [32••]. Owing to the risks of surgery and lack of controlled evidence, the European Headache Federation has reviewed the use of neuromodulation in $\mathrm{CCH}$. It has recommended that procedures should only be considered when all other medical treatments have failed, should be carried out by tertiary headache centers, and should start with the least invasive methods before considering DBS [39].

\section{PH}

$\mathrm{PH}$ is characterized by attacks of severe, strictly unilateral pain occurring in the orbital or temporal regions that last for 2 30 minutes and occur several or many times a day accompanied by autonomic symptoms. The condition responds completely to indometacin (Table 1) [1].

Acute medications are often of little use in this condition as the attacks are too short lasting for any to take effect.

Preventative Medication

\section{Oral Drugs}

By definition, $\mathrm{PH}$ must show an absolute response to indometacin and the diagnosis reconsidered if this response is not seen [1]. Likewise, any patient requiring escalating doses or suddenly becoming unresponsive to indometacin should be reviewed for other pathology. The main reason to use alternative treatments in this condition is the poor tolerability of long-term indometacin, with $30 \%$ of patients developing gastrointestinal (GI) side effects (Table 3) [40].

Cyclooxygenase (COX)-2 inhibitors are reported to have a lower rate of GI side effects but should still be used with caution in those with peptic ulcer disease. Case series from two groups have shown some efficacy using celecoxib and rofecoxib [41, 42]. Case reports also support the use of 
Table 3 Summary of evidence for oral and injectable alternative treatments for paroxysmal hemicrania $(\mathrm{PH})$ and hemicrania continua $(\mathrm{HCl0}$

\begin{tabular}{|c|c|c|c|}
\hline & $n$ & Outcome & Dosing details \\
\hline \multicolumn{4}{|l|}{ PH } \\
\hline \multicolumn{4}{|l|}{ COX-2 inhibitors } \\
\hline \multicolumn{4}{|l|}{ Celecoxib } \\
\hline Mathew et al. [41] & 1 & Positive with 3-month follow-up & 400 mg daily \\
\hline \multicolumn{4}{|l|}{ Rofecoxib } \\
\hline Lisotto et al. [42] & 2 & $\begin{array}{l}\text { Positive } 2 / 2 \text { with } 8-14 \text {-month } \\
\text { follow-up }\end{array}$ & $25-50 \mathrm{mg}$ daily \\
\hline \multicolumn{4}{|l|}{ Topiramate } \\
\hline Cohen et al. [43], Camarda et al. [44] & 2 & $\begin{array}{l}\text { Positive with 6-month-2-year } \\
\text { follow-up }\end{array}$ & 25-200 mg daily \\
\hline \multicolumn{4}{|l|}{ Verapamil } \\
\hline Evers et al. [45] & 10 & Positive $4 / 10$ & Maximum $320 \mathrm{mg}$ daily \\
\hline \multicolumn{4}{|l|}{ Flunarazine } \\
\hline Coria et al. [46] & 5 & Positive 5/5 with 6-month follow-up & \\
\hline \multicolumn{4}{|l|}{ Nerve blocks } \\
\hline \multicolumn{4}{|l|}{ GON } \\
\hline Rossi et al. [47] & 1 & $\begin{array}{l}\text { Positive to } 5 \text { injections over } \\
20 \text { months }\end{array}$ & Methylprednisolone and lidocaine \\
\hline \multicolumn{4}{|l|}{ GON, LON, or SON } \\
\hline Antonaci et al. [48] & 6 & Negative in all & Lidocaine \\
\hline \multicolumn{4}{|l|}{$\mathrm{HC}$} \\
\hline \multicolumn{4}{|l|}{ COX-2 inhibitors } \\
\hline \multicolumn{4}{|l|}{ Rofecoxib } \\
\hline Peres et al. [52], Muller et al. [51] & 10 & Positive 4/9 & $25-50 \mathrm{mg}$ daily \\
\hline \multicolumn{4}{|l|}{ Celcoxib } \\
\hline Peres et al. [52] & 5 & Positive $4 / 5$ & $800 \mathrm{mg}$ daily \\
\hline \multicolumn{4}{|l|}{ Melatonin } \\
\hline $\begin{array}{l}\text { Rozen [53], Spears [54], Hollingworth } \\
\text { et al. [55] }\end{array}$ & $\begin{array}{l}5 \text { (1 patient not trial } \\
\text { indometacin) }\end{array}$ & $\begin{array}{l}\text { Positive } 5 / 5 \text { with } 3-5 \text {-month } \\
\text { follow-up }\end{array}$ & 9-15 mg daily \\
\hline \multicolumn{4}{|l|}{ Topiramate } \\
\hline $\begin{array}{c}\text { Camarda et al. [44], Matharu et al. [56], } \\
\text { Brighna et al. [57], Prakash et al. [58] }\end{array}$ & 6 & $\begin{array}{l}\text { Positive with follow-up of } 6 \text { weeks- } \\
1 \text { year }\end{array}$ & 100-200 mg daily \\
\hline \multicolumn{4}{|l|}{ Verapamil } \\
\hline Rozen [59], Rajabally and Jacob [60] & 2 & $\begin{array}{l}\text { Positive with follow-up of } \\
8-9 \text { months }\end{array}$ & $120-480 \mathrm{mg}$ daily \\
\hline \multicolumn{4}{|l|}{ Gabapentin } \\
\hline $\begin{array}{l}\text { Prakesh et al. [58], Moura et al. [61], } \\
\text { Spears [62] }\end{array}$ & 12 & $\begin{array}{l}\text { Positive } 10 / 12 \text { with } 2-13 \text {-month } \\
\text { follow-up }\end{array}$ & $600-3600 \mathrm{mg}$ daily \\
\hline \multicolumn{4}{|l|}{ Nerve blocks } \\
\hline \multicolumn{4}{|l|}{ SON, trochlear, GON, LON } \\
\hline Guerrero et al. [63] & 9 & $\begin{array}{l}\text { Positive } 9 / 9 \\
\text { ( } 5 / 9 \text { pain free) }\end{array}$ & $\begin{array}{l}\text { Bupivacaine, mepivacane, or } \\
\text { triamcinolone }\end{array}$ \\
\hline \multicolumn{4}{|l|}{ GON, LON, or SON } \\
\hline Antonaci et al. [48] & 7 at each site & $\begin{array}{l}\text { Positive } 4 / 7 \text { SON, negative GON } \\
\text { and LON }\end{array}$ & Lidocaine \\
\hline \multicolumn{4}{|l|}{ Botulinum toxin } \\
\hline Khali et al. [64], Garza and Cutrer [65] & 2 & Positive over 3-4 injection cycles & $100-155$ units \\
\hline
\end{tabular}

$C O X-2$ cyclooxygenase 2, GON greater occipital nerve, $L O N$ lesser occipital nerve, $S O N$ supraorbital nerve

topiramate, with two patients reporting continued remission after 2 years [43, 44]. Calcium channel blockers have also been trialed in open-label series. Verapamil was found by
Evers and Husstedt [45] to have a mild-to-moderate effect, and flunarazine induced complete remission in the five patients treated by Coria et al. [46], with no reported side effects. 


\section{Nerve Blocks}

The use of GON blocks in PH is supported by a single case report by Rossi et al. [47]. Antonaci et al. [48] conducted blocks of the greater occipital, lesser occipital, and supraorbital nerves in six patients with chronic $\mathrm{PH}$ with a negative effect in all. Despite the limited evidence, GON blocks are widely employed in headache clinics for $\mathrm{PH}$ with some success. Obviously, larger studies are needed to support this practice.

\section{Neurostimulation}

Once again, there is very little published evidence on the use of neurostimulation for $\mathrm{PH}$. No reports exist for the use of ONS in PH; however, our local experience is that it may be useful in refractory patients (unpublished data).

Walcott et al. [49] have published a single case of DBS in $\mathrm{PH}$. The patient had an immediate and complete response to DBS, with the pain returning within hours after stopping DBS. With a follow-up period of 2 years, the device had retained its efficacy. On the basis of such limited evidence, neurostimulation should only be considered in patients who have failed all possible medical treatments mentioned above.

\section{HC}

It is only recently that $\mathrm{HC}$ has been classified as a TAC, having previously been considered a separate primary headache disorder. The disorder is characterized by persistent, strictly unilateral head pain associated with autonomic features, and that is completely responsive to indometacin (Table 1) [1].

Acute medications, including oxygen and triptans, have generally been reported to be of little use in this condition [50].

Preventative Treatments

\section{Oral Treatments}

By definition, $\mathrm{HC}$ must show a complete response to indometacin and the diagnosis reconsidered if this is not seen. The poor tolerability of indometacin is the main reason alternatives are sought (Table 3 ).

Once again, the evidence is limited to case reports, but oral drugs that may prove useful include COX-2 inhibitors (Rofecoxib and Celecoxib) [51, 52], melatonin [53-55], topiramate [44, 56-58], verapamil [59, 60], and gabapentin $[58,61,62]$.

\section{Injectable Treatments}

The use of nerve blocks in $\mathrm{HC}$ is supported by two case series using multiple cranial nerve blocks. Guerrero et al. [63] used combinations of supraorbital, trochlear, and greater and lesser occipital nerve blocks with good effect, and Antonaci et al. [48] suggested that the positive response of $\mathrm{HC}$ to supraorbital nerve blocks could be used to differentiate it from $\mathrm{PH}$. Antonaci et al. [48] found that GONBs were ineffective in their patient group; however, in our experience, patients often respond well and our practice is to offer this treatment.

Limited case reports exist for the efficacy of botulinum toxin in $\mathrm{HC}[64,65]$. However, our local experience of good results in $5 / 7$ patients suggests that it can be useful and should be considered in resistant cases (unpublished data).

\section{Neurostimulation}

There are three case series and reports of neuromodulation in HC. Burns et al. [66] and Schwedt et al. [67] implanted a BION device in a total of seven patients, with five reporting $>50 \%$ improvement. Schwedt et al. [68] also included two HC patients in their series of 15 ONS implantations and although individual results for this headache type is not given in the paper, the group quote a mean reduction of headache frequency of one-third across the series.

\section{Short-Lasting Unilateral Neuralgiform Headache Attacks}

These conditions consist of attacks of moderate or severe, strictly unilateral head pain lasting seconds to minutes, which occur at least once a day and are usually associated with prominent lacrimation and redness of the ipsilateral eye [1]. Two subtypes are recognized in the International Classification for Headache Disorders-3 beta: SUNCT and SUNA. The differentiation is made on the associated autonomic features; patients with SUNCT exhibit both conjunctival injection and tearing, whereas patients with SUNA will have only one or neither of them (Table 1). Attacks are so brief that acute medication is of little use to patients.

Preventative Medication

\section{Oral Treatments}

Current guidelines for the preventative treatment of shortlasting unilateral neuralgiform headache attacks advise firstline treatment with lamotrigine $[2,69]$. Other oral therapies, including topiramate, gabapentin, oxcarbazepine, carbamazepine, and mexiletine all have case reports to support their use as alternative agents (Table 4). 
Table 4 Summary of evidence for oral and injectable alternative treatments for short-lasting unilateral neuralgiform headache attacks

\begin{tabular}{|c|c|c|c|}
\hline & $n$ & Outcome & Dosing details \\
\hline \multicolumn{4}{|l|}{ Topiramate } \\
\hline Kuhn et al. [70], Matharu et al. [71], Rossi et al. [72] & 4 & Positive $4 / 4$ with follow-up of $5-9$ months & 50-200 mg daily \\
\hline \multicolumn{4}{|l|}{ Gabapentin } \\
\hline Etemadifar et al. [73] & 8 & $\begin{array}{l}\text { Positive } 8 / 8 \\
\text { ( } 5 \text { pain free) }\end{array}$ & $600-900 \mathrm{mg}$ daily \\
\hline \multicolumn{4}{|l|}{ Carbamazepine } \\
\hline Matharu et al. $[74]^{\mathrm{a}}$ & 33 & Complete or partial response 11/33 (alone or combination) & $600-3000 \mathrm{mg}$ daily \\
\hline \multicolumn{4}{|l|}{ Oxcarbazepine } \\
\hline Marziniak et al. [75], Dora [76] & 2 & Positive $2 / 2$ with follow up $1-36$ months & $600 \mathrm{mg}$ daily \\
\hline \multicolumn{4}{|l|}{ Intravenous lidocaine } \\
\hline Matharu et al. [77] & 4 & Positive $4 / 4$ & $1-3 \mathrm{mg} / \mathrm{min}$ \\
\hline \multicolumn{4}{|l|}{ Botulinum toxin } \\
\hline Zabalza [79] & 1 & Positive after 3 years of 3-monthly injections & Injections around orbit \\
\hline \multicolumn{4}{|l|}{ Nerve blocks } \\
\hline \multicolumn{4}{|l|}{ GON } \\
\hline Porta-Essam et al. [80] & 1 & Positive & Bupivacaine \\
\hline Pareja et al. [81] & 3 & Negative & Lidocaine \\
\hline \multicolumn{4}{|l|}{ SON } \\
\hline Pareja et al. [81] & 7 & Negative & Lidocaine \\
\hline
\end{tabular}

GON greater occipital nerve, SON supraorbital nerve

${ }^{\mathrm{a}}$ Review article

Kuhn et al. [70], Matharu et al. [71], and Rossi et al. [72] have reported a total of four patients achieving freedom from pain on low doses of topiramate. Our experience is that higher doses are often required to gain control of the condition.

Gabapentin has been reported in one open-label study and three case reports to be efficacious in short-lasting unilateral neuralgiform headache attacks. The open-label study conducted by Etemadifar et al. [73] consisted of eight patients all who responded well, with five becoming pain free on $600 \mathrm{mg}$ daily.

Carbamazepine is first-line treatment for trigeminal neuralgia, and given the clinical similarities and high misdiagnosis rates between conditions a number of patients have been trialed successfully on the drug in the clinical setting. Matharu et al. [74] reviewed 33 patients given carbamazepine. Twentytwo had no response and only three patients reported a complete response to carbamazepine either alone or in combination with other drugs. Oxcarbazepine, a structural derivative of carbamazepine, is a drug we frequently use locally for short-lasting unilateral neuralgiform headache attacks as it appears to be well tolerated and as efficacious as carbamazepine. However, only two case reports exist in the literature to support its use $[75,76]$.

\section{Injectable Treatments and Nerve Blocks}

Intravenous lidocaine is a useful agent in the treatment of severe attacks or short-lasting unilateral neuralgiform headache attack status. Matharu et al. [77] reported a series of four intractable patients rendered pain free by the infusion. The use of lidocaine and mexiletine, both antiarrthmyic drugs acting on sodium channels, are reviewed in a paper by Marmura [78].

Limited reports exist on the use of botulinum toxin and GONB for short-lasting unilateral neuralgiform headache attacks [79-81]. Our local experience is that GONB can be useful in a small subset of patients.

\section{Resectional and Ablative Surgery}

A number of procedures have been conducted over the years, often under the misdiagnosis of trigeminal neuralgia, including microvascular decompression, glycerol rhizotomy, trigeminal nerve radiofrequency ablation, balloon compression of the Gasserion ganglion, and Gamma knife therapy. Outcomes are mixed but, in general, the adverse effects outweigh any benefit. The one procedure that has appeared in recent reviews to be efficacious, even with long-term follow-up, is microvascular decompression (MVD) of the trigeminal nerve. An Australian group found 19 patients described in the literature undergoing MVD. After a 14-month follow-up, $63 \%$ had complete resolution of pain and the rest had little or no change. Adverse effects included wound infection, vertigo, and jaw pain, and more serious effects of persistent hearing loss and ataxia [82••]. Larger patient numbers and follow-up 
periods are needed, but MVD appears a sensible option in refractory patients with an aberrant vessel on imaging before attempting neuromodulation, which is more expensive and invasive.

\section{Neurostimulation}

A case series of nine patients undergoing ONS for SUNCT/ SUNA was reported by Lambru et al. [83], with eight reporting a positive response and four freedom from pain. Supraorbital and supratrochlear stimulation has also been successful in one patient [84].

The outcomes of DBS for SUNCT appear promising, with three patients gaining substantial relief within a few months of surgery [85-88]. Our own data consist of 5/6 patients treated responding well, with two achieving freedom from pain [89].

\section{Conclusion}

$\mathrm{CH}, \mathrm{PH}, \mathrm{HC}$, and short-lasting unilateral neuralgiform headache attacks are well-defined stereotyped syndromes that can be differentiated by their clinical features and treatment responses. Whilst each syndrome has standard treatment options, there will be a small but disabled group of patients who will be unresponsive to these and require alternative agents. The evidence base for any of these alternative treatments is poor, but a wide variety of oral, injectable, and surgical options does exist. Table 5 summarizes the alternative options used in our clinic. Surgical techniques should be reserved for patients proving intractable to all available medical treatments and, with the exception of SUNCT/SUNA treated with MVD, neurostimulation techniques will be the choice in the future. One treatment that should potentially be made more widely available to TAC patients is GONB. On the basis of highly positive $\mathrm{CH}$ data, the favorable safety profile, and the ease of the procedure, a strong argument can be made for using nerve blocks earlier in the treatment regime or as a bridging therapy in many more patients.

Currently, the most robust evidence exists for the treatment of $\mathrm{CH}$ with the use of GONB, SPG stimulation, and melatonin. DBS appears promising but this is on the basis of increasing numbers of case reports only. It is clear that large randomized trials are needed on all TAC treatments to allow guidelines to be based on efficacy and safety.

\section{Compliance with Ethics Guidelines}

Conflict of Interest Dr. Sarah Miller has received educational grants from St Jude Medical, educational and travel grants from Medtronic, and speaker's fees for Allergen. 
Dr. Manjit Matharu serves on the advisory board for Allergan and St Jude Medical, and has received payment for the development of educational material from Allergan, Merck Sharpe, Dohme Ltd, and Medtronic.

Human and Animal Rights and Informed Consent This article does not contain any studies with human or animal subjects performed by any of the authors.

Open Access This article is distributed under the terms of the Creative Commons Attribution License which permits any use, distribution, and reproduction in any medium, provided the original author(s) and the source are credited.

\section{References}

Papers of particular interest, published recently, have been highlighted as:

- Of importance

- Of major importance

1. Headache Classification Committee of the International Headache S. The International Classification of Headache Disorders, 3rd edition (beta version). Cephalalgia. 2013;33:629-808.

2. May A, Leone M, Afra J, Linde M, Sandor PS, Evers S, et al. EFNS guidelines on the treatment of cluster headache and other trigeminalautonomic cephalalgias. Eur J Neurol. 2006;13:1066-77.

3.• Pareja JA, Alvarez M. The usual treatment of trigeminal autonomic cephalalgias. Headache. 2013;53:1401-14. Recent review article on conventional treatments of trigeminal autonomic cephalalgias.

4. Costa A, Pucci E, Antonaci F, Sances G, Granella F, Broich G, et al. The effect of intranasal cocaine and lidocaine on nitroglycerininduced attacks in cluster headache. Cephalalgia. 2000;20:85-91.

5. Matharu MS, Levy MJ, Meeran K, Goadsby PJ. Subcutaneous octreotide in cluster headache: randomized placebo-controlled double-blind crossover study. Ann Neurol. 2004;56:488-94.

6. Leandri M, Luzzani M, Cruccu G, et al. Drug-resistant cluster headache responding to gabapentin: a pilot study. Cephalalgia. 2001;21:744-6.

7. Schuh-Hofer S, Israel H, Neeb L, Reuter U, Arnold D. The use of gabapentin in chronic cluster headache patients refractory to firstline therapy. Eur J Neurol. 2007;14:694-6.

8. Silberstein S, Goode-Sellers S, Twomey C, Saiers J, Ascher J. Randomized, double-blind, placebo-controlled, phase II trial of gabapentin enacarbil for migraine prophylaxis. Cephalalgia. 2013;33:101-11

9. Linde M, Mulleners WM, Chronicle EP, McCrory DC. Gabapentin or pregabalin for the prophylaxis of episodic migraine in adults. Cochrane Database Syst Rev. 2013;6, CD010609.

10. Leone M, D'Amico D, Moschiano F, Fraschini F, Bussone G. Melatonin versus placebo in the prophylaxis of cluster headache: a double-blind pilot study with parallel groups. Cephalalgia. 1996;16:494-6.

11. Pringsheim T, Magnoux E, Dobson CF, Hamel E, Aube M. Melatonin as adjunctive therapy in the prophylaxis of cluster headache: a pilot study. Headache. 2002;42:787-92.

12. Hering-Hanit R, Gadoth N. The use of baclofen in cluster headache. Curr Pain Headache Rep. 2001;5:79-82.

13. Hering R, Kuritzky A. Sodium valproate in the treatment of cluster headache: an open clinical trial. Cephalalgia. 1989;9:195-8.

14. El Amrani M, Massiou H, Bousser MG. A negative trial of sodium valproate in cluster headache: methodological issues. Cephalalgia. 2002;22:205-8.
15. Tronvik E, Wienecke T, Monstad I, Dahlof C, Boe MG, Tjensvoll $\mathrm{AB}$, et al. Randomised trial on episodic cluster headache with an angiotensin II receptor blocker. Cephalalgia. 2013;33:1026-34.

16. Palermo A, Giglia G, Cosentino G, Raieli V, Brighina F, Fierro B. Two cases of cluster headache effectively treated with levetiracetam. Funct Neurol. 2013;28:63-4.

17. Sostak P, Krause P, Forderreuther S, Reinisch V, Straube A. Botulinum toxin type-A therapy in cluster headache: an open study. J Headache Pain. 2007;8:236-41.

18. Robbins L. Botulinum toxin A (Botox) for cluster headache: 6 cases. Cephalalgia. 2001;21:492-503.

19. Freund BJ, Schwartz M. The use of Botulinum toxin-A in the treatment of refractory cluster headache: case reports. Cephalalgia. 2000;20:235-331.

20. Smuts JA, Barnard PWA. Botulinum toxin type A in the treatment of headache syndromes: a clinical report on 79 patients. Cephalalgia. 2000;20:332-7.

21. Lambru G, Abu Bakar N, Stahlhut L, McCulloch S, Miller S, Shanahan P, et al. Greater occipital nerve blocks in chronic cluster headache: a prospective open-label study. Eur J Neurol. 2014;338-43.

22. Leroux E, Valade D, Taifas I, Vicaut E, Chagnon M, Roos C, et al. Suboccipital steroid injections for transitional treatment of patients with more than two cluster headache attacks per day: a randomised, double-blind, placebo-controlled trial. Lancet Neurol. 2011;10: 891-7. Randomized, placebo-controlled study into the efficacy of GON blocks in cluster headache.

23. Ambrosini A, Vandenheede M, Rossi P, Aloj F, Sauli E, Pierelli F, et al. Suboccipital injection with a mixture of rapid- and long-acting steroids in cluster headache: a double-blind placebo-controlled study. Pain. 2005;118:92-6. Randomized, placebo-controlled study into the efficacy of GON blocks in cluster headache.

24. Devoghel JC. Cluster headache and sphenopalatine block. Acta Anaesthesiol Belg. 1981;32:101-7.

25. Pipolo C, Bussone G, Leone M, Lozza P, Felisati G. Sphenopalatine endoscopic ganglion block in cluster headache: a reevaluation of the procedure after 5 years. Neurol Sci. 2010;31 Suppl 1:S197-9.

26. Jarrar RG, Black DF, Dodick DW, Davis DH. Outcome of trigeminal nerve section in the treatment of chronic cluster headache. Neurology. 2003;60:1360-2.

27. Matharu M, Goadsby PJ. Persistence of attacks of cluster headache after trigeminal nerve root section. Brain. 2002;125:976-84.

28. Kano H, Kondziolka D, Mathieu D, Stafford S, Flannery T, Niranjan A, et al. Stereotactic radiosurgery for intractable cluster headache: an initial report from the North American Gamma Knife Consortium. J Neurosurg. 2011;114:1736-43.

29. McClelland 3rd S, Tendulkar RD, Barnett GH, Neyman G, Suh JH. Long-term results of radiosurgery for refractory cluster headache. Neurosurgery. 2006;59:1258-62.

30. Burns B, Watkins L, Goadsby PJ. Treatment of intractable chronic cluster headache by occipital nerve stimulation in 14 patients. Neurology. 2009;72:341-5. First report of ONS in CCH.

31. Magis D, Gerardy PY, Remacle JM, Schoenen J. Sustained effectiveness of occipital nerve stimulation in drug-resistant chronic cluster headache. Headache. 2011;51:1191-201.

32.• Magis D, Schoenen J. Advances and challenges in neurostimulation for headaches. Lancet Neurol. 2012;11:708-19. Review article on all forms of neurostimulation for primary headache disorders, including trigeminal autonomic cephalalgias.

33. Ansarinia M, Rezai A, Tepper SJ, Steiner CP, Stump J, StantonHicks M, et al. Electrical stimulation of sphenopalatine ganglion for acute treatment of cluster headaches. Headache. 2010;50:1164-74.

34.• Schoenen J, Jensen RH, Lanteri-Minet M, Lainez MJ, Gaul C, Goodman AM, et al. Stimulation of the sphenopalatine ganglion (SPG) for cluster headache treatment. Pathway CH-1: A randomized, sham-controlled study. Cephalalgia. 2013;33:816-30. Shamcontrolled study on the use of sphenopalatine ganglion stimulation 
for acute treatment of cluster headache and it's potential as a preventative treatment.

35. May A, Bahra A, Büchel C, et al. Hypothalamic activation in cluster headache attacks. Lancet. 1998;352:275-8.

36. Leone M, Franzini A, Bussone G. Stereotactic stimulation of posterior hypothalamic gray matter in a patient with intractable cluster headache. N Engl J Med. 2001;345:1428-9.

37. Fontaine D, Lazorthes Y, Mertens P, et al. Safety and efficacy of deep brain stimulation in refractory cluster headache: a randomized placebo-controlled double-blind trial followed by a 1 year open extension. J Headache Pain. 2010;11:23-31.

38. Schoenen J, Di Clemente L, Vandenheede M, Fumal A, De Pasqua $\mathrm{V}$, Mouchamps M, et al. Hypothalamic stimulation in chronic cluster headache: a pilot study of efficacy and mode of action. Brain. 2005;128:940-7.

39. Martelletti P, Jensen RH, Antal A, Arcioni R, Brighina F, de Tommaso M, et al. Neuromodulation of chronic headaches: position statement from the European Headache Federation. J Headache Pain. 2013;14:86.

40. Pareja JA, Caminero AB, Franco E, Casado JL, Pascual J, Sanchez del Rio M. Dose, efficacy and tolerability of long-term indomethacin treatment of chronic paroxysmal hemicrania and hemicrania continua. Cephalalgia. 2001;21:906-10.

41. Mathew NT, Kailasam J, Fischer A. Responsiveness to celecoxib in chronic paroxysmal hemicrania. Neurology. 2000;55:316.

42. Lisotto C, Maggioni F, Mainardi F, Zanchin G. Rofecoxib for the treatment of chronic paroxysmal hemicrania. Cephalalgia. 2003;23: 318-20.

43. Cohen AS, Goadsby PJ. Paroxysmal hemicrania responding to topiramate. J Neurol Neurosurg Psychiatry. 2007;78:96-7.

44. Camarda C, Camarda R, Monastero R. Chronic paroxysmal hemicrania and hemicrania continua responding to topiramate: two case reports. Clin Neurol Neurosurg. 2008;110:88-91.

45. Evers S, Husstedt IW. Alternatives in drug treatment of chronic paroxysmal hemicrania. Headache. 1996;36:429-32.

46. Coria F, Claveria LE, Jimenez-Jimenez FJ, de Seijas EV. Episodic paroxysmal hemicrania responsive to calcium channel blockers. J Neurol Neurosurg Psychiatry. 1992;55:166.

47. Rossi P, Di Lorenzo G, Faroni J, Sauli E. Seasonal, extratrigeminal, episodic paroxysmal hemicrania successfully treated with single suboccipital steroid injections. Eur J Neurol. 2005;12:903-6.

48. Antonaci F, Pareja JA, Caminero AB, Sjaastad O. Chronic paroxysmal hemicrania and hemicrania continua: anaesthetic blockades of pericranial nerves. Funct Neurol. 1997;12:11-5.

49. Walcott BP, Bamber NI, Anderson DE. Successful treatment of chronic paroxysmal hemicrania with posterior hypothalamic stimulation: technical case report. Neurosurgery. 2009;65:E997.

50. Cittadini E, Matharu MS, Goadsby PJ. Paroxysmal hemicrania: a prospective clinical study of 31 cases. Brain. 2008;131:1142-55.

51. Muller KI, Bekkelund SI. Hemicrania continua changed to chronic paroxysmal hemicrania after treatment with cyclooxygenase-2 inhibitor. Headache. 2011;51:300-5.

52. Peres MF, Silberstein SD. Hemicrania continua responds to cyclooxygenase-2 inhibitors. Headache. 2002;42:530-1.

53. Rozen TD. Melatonin responsive hemicrania continua. Headache. 2006;46:1203-4.

54. Spears RC. Hemicrania continua: a case in which a patient experienced complete relief on melatonin. Headache. 2006;46:524-7.

55. Hollingworth M, Young TM. Melatonin responsive hemicrania continua in which indomethacin was associated with contralateral headache. Headache. 2014;54:916-9.

56. Matharu MS, Bradbury P, Swash M. Hemicrania continua: side alternation and response to topiramate. Cephalalgia. 2006;26:341-4.

57. Brighina F, Palermo A, Cosentino G, Fierro B. Prophylaxis of hemicrania continua: two new cases effectively treated with topiramate. Headache. 2007;47:441-3.
58. Prakash S, Husain M, Sureka DS, Shah NP, Shah ND. Is there need to search for alternatives to indomethacin for hemicrania continua? Case reports and a review. J Neurol Sci. 2009;277:187-90.

59. Rozen TD. Verapamil-responsive hemicrania continua in a patient with episodic cluster headache. Cephalalgia. 2006;26:351-3.

60. Rajabally YA, Jacob S. Hemicrania continua responsive to verapamil. Headache. 2005;45:1082-3.

61. Moura LM, Bezerra JM, Fleming NR. Treatment of hemicrania continua: case series and literature review. Rev Bras Anestesiol. 2012;62:173-87.

62. Spears RC. Is gabapentin an effective treatment choice for hemicrania continua? J Headache Pain. 2009;10:271-5.

63. Guerrero AL, Herrero-Velazquez S, Penas ML, Mulero P, Pedraza MI, Cortijo E, et al. Peripheral nerve blocks: a therapeutic alternative for hemicrania continua. Cephalalgia. 2012;32:505-8.

64. Khalil M, Ahmed F. Hemicrania continua responsive to botulinum toxin type a: a case report. Headache. 2013;53:831-3.

65. Garza I, Cutrer FM. Pain relief and persistence of dysautonomic features in a patient with hemicrania continua responsive to botulinum toxin type A. Cephalalgia. 2010;30:500-3.

66. Burns B, Watkins L, Goadsby PJ. Treatment of hemicrania continua by occipital nerve stimulation with a bion device: long-term followup of a crossover study. Lancet Neurol. 2008;7:1001-12.

67. Schwedt TJ, Dodick DW, Trentman TL, Zimmerman RS. Occipital nerve stimulation for chronic cluster headache and hemicrania continua: pain relief and persistence of autonomic features. Cephalalgia. 2006;26:1025-7.

68. Schwedt TJ, Dodick DW, Hentz J, Trentman TL, Zimmerman RS Occipital nerve stimulation for chronic headache-long-term safety and efficacy. Cephalalgia. 2007;27:153-7.

69. SIGN. Diagnosis and management of headache in adults. A national clinical guideline. In: Network SIG, editor. 2008. Retrieved from http://www.sign.ac.uk/guidelines/fulltext/107.

70. Kuhn J, Vosskaemper M, Bewermeyer H. SUNCT syndrome: a possible bilateral case responding to topiramate. Neurology. 2005;64:2159.

71. Matharu MS, Boes CJ, Goadsby PJ. SUNCT syndrome: prolonged attacks, refractoriness and response to topiramate. Neurology. 2002;58:1307.

72. Rossi P, Cesarino F, Faroni J, Malpezzi MG, Sandrini G, Nappi G. SUNCT syndrome successfully treated with topiramate: case reports. Cephalalgia. 2003;23:998-1000.

73. Etemadifar M, Maghzi AH, Ghasemi M, Chitsaz A, Kaji Esfahani M. Efficacy of gabapentin in the treatment of SUNCT syndrome. Cephalalgia. 2008;28:1339-42.

74. Matharu MS, Cohen AS, Boes CJ, Goadsby PJ. Short-lasting unilateral neuralgiform headache with conjunctival injection and tearing syndrome: a review. Curr Pain Headache Rep. 2003;7:308-18.

75. Marziniak M, Breyer R, Evers S. SUNCT syndrome successfully treated with the combination of oxcarbazepine and gabapentin. Pain Med. 2009;10:1497-500.

76. Dora B. SUNCT syndrome with dramatic response to oxcarbazepine. Cephalalgia. 2006;26:1171-3.

77. Matharu MS, Cohen AS, Goadsby PJ. SUNCT syndrome responsive to intravenous lidocaine. Cephalalgia. 2004;24:985-92.

78. Marmura MJ. Intravenous lidocaine and mexiletine in the management of trigeminal autonomic cephalalgias. Curr Pain Headache Rep. 2010;14:145-50.

79. Zabalza RJ. Sustained response to botulinum toxin in SUNCT syndrome. Cephalalgia. 2012;32:869-72.

80. Porta-Etessam J, Cuadrado ML, Galan L, Sampedro A, Valencia C. Temporal response to bupivacaine bilateral great occipital block in a patient with SUNCT syndrome. J Headache Pain. 2010;11:179.

81. Pareja JA, Kruszewski P, Sjaastad O. SUNCT syndrome: trials of drugs and anesthetic blockades. Headache. 1995;35:138-42. 
82.• Sebastian S, Schweitzer D, Tan L, Broadley SA. Role of trigeminal microvascular decompression in the treatment of SUNCT and SUNA. Curr Pain Headache Rep. 2013;17:332. Review of the evidence for MVD for SUNCT and SUNA.

83. Lambru G, Shanahan P, Watkins L, Matharu MS. Occipital nerve stimulation in the treatment of medically intractable SUNCT and SUNA. Pain Phys. 2014;17:29-41.

84. Vaisman J, Markley H, Ordia J, Deer T. The treatment of medically intractable trigeminal autonomic cephalalgia with supraorbital/ supratrochlear stimulation: a retrospective case series. Neuromodulation. 2012;15:374-80.

85. Bartsch T, Falk D, Knudsen K, Reese R, Raethjen J, Mehdorn HM, et al. Deep brain stimulation of the posterior hypothalamic area in intractable short-lasting unilateral neuralgiform headache with conjunctival injection and tearing (SUNCT). Cephalalgia. 2011;31:1405-8.
86. Black DF, Dodick DW. Two cases of medically and surgically intractable SUNCT: a reason for caution and an argument for a central mechanism. Cephalalgia. 2002;22:201-4.

87. Leone M, Franzini A, D'Andrea G, Broggi G, Casucci G, Bussone G. Deep brain stimulation to relieve drug-resistant SUNCT. Ann Neurol. 2005;57:924-7.

88. Lyons MK, Dodick DW, Evidente VG. Responsiveness of shortlasting unilateral neuralgiform headache with conjunctival injection and tearing to hypothalamic deep brain stimulation. J Neurosurg. 2009; 110:279-81.

89. Miller S, Rasul F, Lambru G, Lagrata S, Hariz GM, Zrinzo L, et al. Posterior hypothalamic region deep brain stimulation in shoer lasting unilateral neuralgiform headache with conjunctival injection and tearing (SUNCT). Cephalalgia. 2013;33(8 Suppl):1-309. 